\title{
PENGARUH PERMAINAN GOBAK SODOR TERHADAP KEMAMPUAN JASMANI ANAK
}

\author{
Acep Ruswan 1), Gia Nikawanti²)
}

Pendidikan Guru Sekolah Dasar, Universitas Pendidikan Indonesia, Kampus Purwakarta1)

STKIP Purwakarta²)

\section{Kata Kunci :}

Permainan gobak sodor Bermain

Kemampuan jasmani

\begin{abstract}
This research was conducted to find out the influence of gobak sodor game to increase the physical ability of children. This research uses quantitative method with quasi experiment design. The population in this research is the students of class I-III SD with age range 6-9 year by using research sample of 60 students consist of 30 students of experiment class and 30 students of control class. The test of this hypothesis aims to determine whether or not the influence of gobak sodor game to increase the physical ability of children. From result of hypothesis testing known t count equal to 4,243 with significance $\alpha=$ 0,05 while t table 2,00. So t arithmetic $\geq t$ table then Ho is rejected and Ha accepted. It can be proven that gobak sodor game can improve the physical ability of children.
\end{abstract}

Email penulis:

gyanikawanti@upi.edu

\begin{abstract}
ABSTRAK
Penelitian ini dilakukan untuk mengetahi pengaruh permainan gobak sodor terhadap peningkatan kemampuan jasmani anak. Penelitian ini menggunakan metode kuantitatif dengan desain eksperimen semu (quasi eksperiment). Populasi dalam penelitian ini adalah siswa kelas I-III SD dengan rentang usia 6-9 tahun dengan menggunakan sampel penelitian sebanyak 60 orang siswa terdiri dari 30 orang siswa kelas eksperimen dan 30 orang siswa kelas kontrol. Uji hipotesis ini bertujuan untuk mengetahui ada atau tidaknya pengaruh permainan gobak sodor terhadap peningkatan kemampuan jasmani anak. Dari hasil pengujian hipotesis diketahui t hitung sebesar 4,243 dengan signifikasi $\alpha=0,05$ sedangkan $\mathrm{t}$ tabel 2,00. Sehingga t hitung $\geq \mathrm{t}$ tabel maka Ho ditolak dan Ha diterima. Berarti dapat dibuktikan bahwa permaianan gobak sodor dapat meningkatkan kemampuan jasmani anak.
\end{abstract}

\section{PENDAHULUAN}

Pemberian stimulus sedari dini sangat penting bagi tumbuh kembang anak karena di saat inilah tumbuh kembang anak baik fisik, psikis dan kognitif sedang berkembang dengan pesat. Stimulus-stimulus tersebut harus diberikan oleh orang tua, guru, dan lingkungannya. Orang tua dan orang dewasa di sekitar anak harus mengamati tingkat perkembangan anak dan merencanakan berbagai kegiatan yang bisa menstimulasinya. Pemberian stimulasi untuk mengembangkan kemampuan fisik- motorik serta mengembangkan kreativitas pada anak merupakan hal yang penting. Kemampuan jasmani merujuk kepada kemampuan untuk 
mengkoordinasikan bagian-bagian tubuh seseorang dengan otak supaya berfungsi secara sinkron untuk mencapai tujuan fisik. Dasar yang penting untuk membangun kemampuan jasmani yang baik dalam diri seseorang adalah peningkatan keterampilan gerak seseorang (Mahendra, 2007).

Pada saat anak mencapai kematangan untuk terlibat secara aktif dalam aktivitas fisik yang ditandai dengan kesiapan dan motivasi yang tinggi, dan seiring dengan hal tersebut, orang tua dan guru perlu memberikan berbagai kesempatan dan pengalaman yang dapat meningkatkan keterampilan jasmani anak secara optimal.

Peluang-peluang tersebut tidak saja berbentuk membiarkan anak melakukan kegiatan fisik, akan tetapi perlu juga didukung dengan berbagai fasilitas yang berguna bagi pengembangan keterampilan jasmani. Lutan (2001) menjelaskan bahwa anak yang kurang mendapatkan kesempatan dalam mengembangkan keterampilan motorik pada waktu anak siap untuk melakukan kegiatan tersebut maka pada tingkat perkembangan selanjutnya kurang tertarik dengan aktivitas-aktivitas jasmani seperti olahraga dan aktivitas lainnya.

Maka dari itu untuk mendapatkan pengalaman secara luas maka anak perlu melakukan berbagai kegiatan bermain seperti melompat berulang-ulang, berlari mengelilingi ruangan atau halaman, bergantung, mencoret-coret kertas, merobek-robek kertas, menggambar, menyusun balok menjadi suatu bangunan dan sebagainya. Pengalaman dalam berbagai kegiatan bermain yang dilakukan anak ini sangat bermanfaat untuk meningkatan kemampuan jasmani anak. Berlandaskan penjelasan di atas peneliti ingin melakukan penelitian tentang pengaruh permainan gobak sodor terhadap peningkatan kemampuan jasmani anak.

\section{KAJIAN TEORITIK}

\section{Bermain}

Bermain adalah kegiatan menyenangkan yang sangat dibutuhkan dalam kehidupan manusia guna melepaskan dorongan di dalam diri. Musfiroh (2008) menjelaskan bahwa bermain adalah aktivitas jasmani yang dilakukuan dengan cara bersuka ria agar menghasilkan rasa bahagia di dalam diri individu. Bermain bersifat sukarela, dipilih oleh anak itu sendiri. Bermain juga berpengaruh terhadap aspek perkembangan seperti kognitif, bahasa, pengetahuan tentang dunia, persepsi, perkembangan gerakan tubuh, perkembangan sosial dan emosi.

Bermain memungkinkan anak bergerak secara bebas sehingga anak mampu mengembangkan kemampuan fisik-motoriknya. Santrock (2007) memaparkan pengaruh bermain dalam perkembangan fisik-motorik anak sebagai berikut, 1) Melalui keterampilan motorik, anak dapat menghibur dirinya dan memperoleh perasaan senang. 2) Anak dapat bergerak dari satu tempat ke tempat lainnya dan dapat berbuat sendiri untuk dirinya. Kondisi ini dapat menunjang rasa percaya diri anak. 3) Anak dapat menyesuaikan dirinya dengan lingkungan. 4) Perkembangan motorik yang normal memungkinkan anak dapat bermain atau bergaul dengan teman sebayanya. 5) Perkembangan motorik sangat penting bagi perkembangan kepribadian anak.

\section{Pengembangan Kemampuan Jasmani Anak}

Pengembangan kemampuan jasmani adalah suatu proses kegiatan seseorang yang menghasilkan cara baru di dalam mempelajari gerakan, melalui langkah-langkah perencanaan, pelaksanaan, dan penyempurnaan berdasarkan penilaian yang dilakukan secara terus menerus selama kegiatan itu berlangsung. Sedangkan kemampuan jasmani adalah kesanggupan seseorang untuk menggerakan anggota badan di dalam mempelajari gerakan 
hingga memiliki rangkaian urutan gerak yang teratur, luwes, cepat, tepat, dan lancar melalui latihan yang teratur dan terus menerus.

Di pendidikan dasar pengembangan kemampuan jasmani anak difokuskan pada keterampilan lokomotor, non-lokomotor dan manipulasi. Minat melakukan aktivitas fisik pada anak sekolah dasar sangat dipengaruhi oleh kesempatan untuk melakukan aktivitas fisik itu sendiri. Permainan yang biasanya diminati oleh anak usia sekolah dasar adalah permainan yang didominasi permainan aktif seperti bermain kejar-kejaran, petak umpet, dan beberapa bentuk permainan tradisonal. Seperti yang dijelaskan oleh Sugiyanto \& Sudjarwo (1991) yang menjelaskan bahwa minat terhadap aktivitas fisik dan atau olah raga anak usia dasar sangat dipengaruhi oleh lingkungan sekitar anak dan kebutuhan perkembangan fisik-motorik serta sosialnya.

\section{Permainan Dalam Pendidikan Jasmani}

Bermain merupakan salah satu wadah pendidikan yang dapat memberikan suasana menyenangkan bagi anak. Dalam pendidikan jasmani bermain berfungsi sebagai alat pendidikan untuk mencapai tujuan pendidikan yang diharapkan dalam memacu pertumbuhan dan perkembangan mental dan fisik anak. Permainan adalah perbuatan untuk menghibur hati baik yang mempergunakan alat ataupun tidak mempergunakan alat. Permainan merupakan suatu hal yang banyak disukai kebanyakan anak. Anak-anak lebih mampu berbagi secara jujur dan terbuka mengenai perasaannya dalam sebuah permainan.

Syarifuddin \& Muhadi (1992/1993) menyatakan bahwa bermain bagi anak usia SD berkaitan dengan pendidikan jasmani yaitu merupakan suatu kebutuhan yang sangat penting dalam kehidupannya, bahkan sebagian dari kehidupan anak usia SD dihabiskan untuk bermain. Bermain untuk anak usia SD berfungsi untuk merangsang dan melatih perkembangan fisikmotoriknya. Sejalan dengan Barrow (1977) yang menjelaskan bahwa pendidikan jasmani bertujuan untuk mengembangkan kemampuan menyesusaiakan jasmaniah, sosial dan mental dari individu. Melalui pendidikan jasmani, siswa disosialisasikan ke dalam aktifitas jasmani termasuk keterampilan berolahraga.

Menurut Soemitro (1992, hlm. 4-7) fungsi bermain dalam penjasorkes dibagi menjadi beberapa jenis, antara lain, 1) Nilai-nilai mental. Setiap anak yang bermain ada nilai-nilai yang dipelajari dengan jalan menghayati dan melaksanakan peraturan dalam permainan. Mereka belajar saling mempercayai di antara kelompoknya. Belajar mengenal kekurangan dirinya jika dibanding dengan orang lain dan mengakui dengan jujur kelebihan orang lain. Belajar mengendalikan nafsu bergerak yang berlebihan dan lain sebagainya. 2) Nilai-nilai fisik. Bergerak yang dilakukan dalam bermain tentu saja disertai kegembiraan. Suasana gembira ini mempunyai pengaruh terhadap keluarnya hormon-hormon yang merangsang pertumbuhan badan. 3) Nilai-nilai sosial. Anak-anak yang bermain dengan gembira, suasana kejiwaannya juga bebas atau lepas dari segala yang merintanginya. Sifat-sifat yang selama ini ditutupi akan nampak mencuat ke atas karena kebiasaan itu. Di dalam permainan dapat saja seorang anak berhadapan dengan seseorang, tetapi dapat pula seorang berhadapan dengan kelompok. Di samping itu dapat juga kelompok dengan kelompok. Di dalam situasi bermain seorang dengan seorang, mereka belajar saling memberi dan menerima.

Oleh karena itu tidaklah mengherankan apabila banyak yang menyakini dan mengatakan bahwa pendidikan jasmani merupakan bagian dari pendidikan menyeluruh, dan sekaligus memiliki potensi yang stategis untuk mengoptimalkan perkembangan jasmani dan rohani anak. 


\section{Permainan Gobak Sodor}

Istilah gobak diartikan dengan jenis permainan anak yang bertempat di sebidang tanah lapang yang telah diberi garis-garis segi empat lalu dibuat menjadi bentuk berupa petakpetak. Permainan gobak dimainkan oleh anak- anak dengan melakukan aktivitas gerak bebas berputar. Anggota dari permainan ini terdiri dari dua regu. Sedangkan isitilah sodor dalam permainan ini berarti penjaga garis sumbu yang membagi dua garis-garis yang melintang dan parallel.

Permainan tradisional gobak sodor merupakan permainan yang dimainkan secara berkelompok dengan anggota sekitar 4-7 orang atau menyesuaikan dengan jumlah kotak dengan aturan tertentu. Permainan ini membutuhkan lapangan yang cukup luas. Lapangannya berbentuk persegi panjang dengan kotak-kotak di dalamnya. Permainan tradisional gobag sodor merupakan permainan yang dimainkan secara berkelompok, oleh karena itu dapat meningkatkan hubungan sosial dengan teman sebaya.

Ruswan (2011) menjelaskan manfaat permainan tradisional gobak sodor yaitu untuk melatih ketrampilan fisik agar menjadi kuat, sehat, dan cakap. Selain itu manfaat permainan tradisional gobag sodor antara lain meningkatkan hubungan sosial dengan teman sebaya, melatih ketrampilan fisik, menumbuhkan kreativitas, sebagai sarana untuk menghibur diri, melatih kecekatan, dan membentuk kepribadian.

Cara bermain gobak sodor dapat dideskripsikan sebagai berikut, 1) Sebelum permainan dimulai tentukan kelompok penjaga dan penyerang. 2) Setiap penjaga menempati garisnya yang telah ditetapkan dengan kedua kakinya harus berada di atas garis. 3) Penyerang memasuki petak dengan berusaha melewati penjaga. 4) Pemain dinyatakan salah apabila kedua kakinya keluar dari garis samping lapangan dan mengganggu jalannya permainan. 5) Pergantian posisi dilakukan apabila seorang pemain penyerang tersentuh pihak penjaga, terjadi kesalahan dari pihak penyerang, dan apabila dalam dua menit tidak terjadi perubahan posisi.

\section{METODE PENELITIAN}

\section{Desain Penelitian}

Penelitian ini menggunakan metode kuantitatif dengan desain eksperimen semu (quasi eksperiment). Desain eksperimen ini dipilih karena mengingat tidak semua variabel (gejala yang muncul) dan kondisi ekperimen dapat diatur dan dikontrol secara ketat. Penelitian ini bertujuan untuk mencari pengaruh permainan gobak sodor terhadap peningkatan kemampuan jasmani anak.

\section{Populasi dan Sampel Penelitian}

Populasi dalam penelitian ini adalah siswa kelas I-III SD dengan rentang usia 6-9 tahun dengan menggunakan sampel penelitian sebanyak 60 orang siswa terdiri dari 30 orang siswa kelas eksperimen dan 30 orang siswa kelas kontrol.

\section{Variabel Penelitian}

Penelitian ini mempunyai dua variabel, yaitu variabel bebas (independent variabel) dan variabel terikat (dependent variabel). Variabel bebas di sini adalah permainan gobak sodor sedangkan untuk variabel terikatnya adalah kemampuan jasmani anak.

\section{Validitas Tes}

Perhitungan validitas dilakukan dengan menggunakan rumus pearson product moment yang dihitung dengan uji-t yaitu: 


$$
r x y=\frac{n \sum X Y-\left(\sum X\right)\left(\sum Y\right)}{\sqrt{\left\{n \sum X^{2}-\left(\sum X\right)^{2}\right\}\left\{n \sum Y^{2}-\left(\sum Y\right)^{2}\right\}}}
$$

Keterangan:

$$
\begin{array}{ll}
\mathrm{rxy} & =\text { koefisien korelasi } \\
\eta & =\text { banyaknya peserta tes } \\
\mathrm{X} & =\text { skor item } \\
\mathrm{Y} & =\text { skor total } \\
\mathrm{t} \text { hitung }= & \frac{\mathrm{r} \sqrt{\mathrm{n}-2}}{\sqrt{1-\mathrm{r}^{2}}} \\
\mathrm{t} & =\mathrm{t} \text { hitung } \\
\mathrm{r} & =\text { koefisien korelasi hasil } \mathrm{r} \text { hitung } \\
\eta & =\text { jumlah responden }
\end{array}
$$

Derajat kebebasan $\mathrm{dk}=60-2=58$ dengan taraf signifikan 5\% maka t-tabel $=2,000$ jika ttabel $<$ t-hitung maka item tes tersebut valid.

\section{Reliabilitas Tes}

Reliabilitas pada penelitian ini menggunakan rumus sebagai berikut:

$$
\begin{aligned}
& \mathrm{r} 11=\frac{2 . r b}{1+r b} \\
& \mathrm{r} 11=\text { koefisien reliabilitas } \\
& \mathrm{rb}=\text { korelasi product moment } \\
& \text { Dengan dk=58 dengan sginifikasi } \alpha=0,05 \text { diketahui } \mathrm{r} \text { tabel= }=0,25 . \\
& \text { Jika } \mathrm{r} 11>\mathrm{r} \text { tabel maka item tes tersebut reliabel } \\
& \text { Jika } \mathrm{r} 11<\mathrm{r} \text { tabel maka item tes tersebut tidak reliabel }
\end{aligned}
$$

\section{HASIL DAN PEMBAHASAN}

\section{Pengujian Persyaratan Analisis}

Pengujian persyaratan analisis dalam penelitian ini bertujuan untuk menguji hipotesis yang mencakup, 1) Pemenuhan persyaratan bahwa data sampel berasal dari populasi berdistribusi normal yang dilakukan melalui pengujian kenormalan data dengan menggunakan uji Lilliefors, 2) Pemenuhan persyaratan kehomogenan varians populasi untuk seluruh kelompok perlakuan dilakukan dengan menggunakan uji Bartlett.

Skor rata-rata tes awal kemampuan gerak pada kelompok permainan gobak sodor sebesar 2,65 dan kelompok permainan kodok dan bangau sebesar 2,67. Data tersebut menunjukan bahwa skor rata-rata dari keduanya tidak jauh berbeda. Maka dari uji perbedaan skor pre test sebelumnya diperoleh daftar distribusi $\mathrm{t}$ untuk $\alpha=0,05 \mathrm{dan} \mathrm{dk}=58$ diperoleh $\mathrm{t}$ tabel $=2,00$ sehingga diketahui bahwa kedua kelompok perlakuan memiliki kemampuan awal yang sama. Kemampuan jasmani anak untuk kelompok yang diberikan permainan gobak sodor secara keseluruhan memiliki rentang skor 3,25-5,00 Melalui permainan gobak sodor kemampuan jasmani anak mempunyai skor rata-rata 4,46; skor modus 4,76; skor median 4,50 dan standar deviasi 0,41.

Sedangkan kemampuan jasmani anak yang diberikan perlakuan secara konvensional dengan menggunakan permainan kodok dan bangau memiliki rentang skor 2,50 - 4,00. Melalui permainan kodok dan bangau kemampuan jasmani anak memperoleh skor rata-rata sebesar 3,26; skor modus 3,26; skor median 3,26 dan standar deviasi 0,52. 
Pengujian Hipotesis:

$$
\begin{aligned}
\mathrm{t} \text { hitung } & =\frac{4,46-3,26}{\sqrt{ } 0,080} \\
& =1,2 \\
& \frac{10,080}{} \\
& =\frac{1,2}{0,283} \\
& =4,243
\end{aligned}
$$

Hipotesis dalam penelitian ini diuji dengan menggunakan uji t. Uji hipotesis ini bertujuan untuk mengetahui ada atau tidaknya pengaruh permainan gobak sodor terhadap kemampuan jasmani anak. Dari hasil pengujian hipotesis diketahui t hitung sebesar 4,243 dengan signifikasi $\alpha=0,05$ sedangkan $t$ tabel 2,00. Sehingga $t$ hitung $\geq t$ tabel maka Ho ditolak dan Ha diterima. Berarti dapat dibuktikan bahwa permianan gobak sodor dapat meningkatkan kemampuan jasmani anak.

\section{KESIMPULAN}

Penelitian ini membuktikan bahwa permainan gobak sodor dapat mempengaruhi peningkatan kemampuan jasmani anak usia sekolah dasar dengan rentang umur 6-9 tahun. Hal ini dapat dilihat dari hasil pengujian hipotesis di mana diketahui t hitung sebesar 4,243 dengan signifikasi $\alpha=0,05$ sedangkan $t$ tabel 2,00 sehingga t hitung $\geq \mathrm{t}$ tabel maka Ho ditolak dan Ha diterima. Berarti dapat dibuktikan bahwa permianan gobak sodor dapat meningkatkan kemampuan jasmani anak.

Dari hasil penelitian ini diharapkan para guru pendidikan jasmani dan kesehatan di Sekolah Dasar dapat lebih kreatif dalam membuat program pembelajaran penjas melalui permainan tradisional Indonesia. Selain itu para guru pendidikan jasmani dan kesehatan dapat mengetahui bahwa permainan tradisional Indonesia khususnya permainan gobak sodor bukan hanya sekedar permainan yang dilakukan untuk kegiatan bersenang-senang belaka tetapi permainan gobak sodor dapat bermanfaat untuk meningkatkan kemampuan jasmani anak.

\section{DAFTAR RUJUKAN}

Barrow, H.M. (1977). Man and movement: principles of physical education. New York: David Mckay Co.

Mahendra, Agus. (2007). Teori belajar mengajar motorik. Bandung: FPOK UPI.

Musfiroh, Tadkirotun. (2008). Cerdas melalui bermain. Jakarta: Grasindo.

Lutan, Rusli. (2001). Asas-asas penjas pendekatan pendidikan gerak di sekolah dasar. Jakarta: Direktorat Jendral Olahraga.

Ruswan, Acep. (2011). Permainan kecil dalam pembelajaran pendidikan jasmani di Sekolah Dasar. Bandung: Royyan Press.

Santrock, W, John. (2007). Child Development. Dallas: Mc Graw Hill.

Sugiyanto \& Sudjarwo (1991). Modul: materi pokok perkembangan dan belajar gerak. Jakarta: Depdikbud.

Soemitro. (1992). Permainan kecil. Jakarta: Depdikbud.

Syarifuddin, Aip, \& Muhadi. (1992/1993). Pendidikan jasmani dan kesehatan. Jakarta: Depdikbud. 